\title{
Covid-19 and E-learning: Factors that influence online classes grasp by Ibn Tofail University's students -
} Morocco

Khaoula JABARI ${ }^{1,7}$, Zakaria ABIDLI ${ }^{2}$, Imane ZEMAMI ${ }^{3}$, Aida SOULAYMANI ${ }^{4}$, Omayma JABARI ${ }^{5}$, Fedoua EL KABSI $^{6}$, Tidiane Diallo ${ }^{1}$, Jumana EL TURK ${ }^{2}$

\author{
${ }^{1}$ Faculty of Pharmacy, University of Sciences, Techniques and Technologies, Bamako, Mali \\ ${ }^{2}$ International University of Casablanca, Casablanca, Morocco \\ ${ }^{3}$ Ibn tofail University, Faculty of Juridical, Economic and social Sciences, Kenitra, 14000, Morocco \\ ${ }^{4}$ Ibn tofail University, Faculty of Sciences, Kenitra, 14000, Morocco \\ ${ }^{5}$ Kassel Universität, Kassel, Germany \\ ${ }^{6}$ Act Coaching, Paris, France \\ ${ }^{7}$ Ibn tofail University, EST, Kenitra, 14000, Morocco
}

\begin{abstract}
This quantitative study is an investigation on distance learning during the lockdown in Morocco following the coronavirus health crisis. This research conducted 145 students of Ibn Tofail University (Kenitra) aims to relate the factors that influence the assimilation of online classes thought via official platforms and the tools to which professors have access. The data analytics tool used for data treatment and analysis in this is SPSS. The results show that the category of the geographic area in which the students live, their psychological state during confinement, the presence of the professor and the availability of the materials and tools necessary to follow the online courses all have a significant impact on assimilation of lessons by students.
\end{abstract}

\section{Introduction}

Today the world is experiencing a significant change due to the recent emergence of the coronavirus during the month of December 2019 in China led to a great health crisis that caused a socio-economic crisis considered as the greatest challenge the world faces since World War II. This health crisis has affected all countries in the world, and has impacted economies, the psychology of citizens, as well as social relationships.

The coronavirus is highly contagious, it has spread quickly to every continent in the world, which forced several countries to take important health measures in order to counter its circulation among citizens. Among these measures, it was recommended to close schools, universities, restaurants and cafes, shops, public transport, etc. The closures of businesses and amenities have given rise to a new / different way of teaching, a new organization of businesses, and less frequent use of public transportation.

The coronavirus reached Morocco in early March 2020 [1], to spread rapidly in the kingdom. As a result, Morocco is one of the countries having very early (March 20, 2020) made the decision to close schools and universities and start distance schooling instead for all levels of education: preschool, primary school, middle school, high school and university. In this article, we focus on distance education in Morocco, and the factors that have influenced the quality of learning among Ibn Tofail university students since Monday March 16, 2020, when confinement in Morocco was first decided to last 3 months, and was later extended by the state of emergency in the country until today.
Distance learning requires the presence of a number of conditions such as internet access, the provision of adequate equipment (computer / tablet / etc.), the psychological preparation of students as well as that of teachers, in addition to the necessity of mastering the tools used for elearning [2]. These elements were investigated in this article with the aim of verifying the factors that influence the uptake of distance learning during the covid-19 health crisis.

Distance education, even when chosen by the student, has many limitations. Students lose motivation and commitment, they are less focused and energetic which impacts their success [3]. This loss of motivation is due to isolation [4] and uncertainty about the near future.

Given the peculiarity of the conditions that characterize learning during this period, we focused our research on works that investigate particularly the subject of e-learning during today's coronavirus crisis.

\section{Data and methods}

This is a cross-sectional study conducted between April and May 2020. To meet our goal, we distributed an online survey sheet to students at Ibn Tofail University. This study is based on the telematics technique, the principle of which is to collect responses via the internet after contacting participants via their institutional email addresses (first name.lastname@uit.ac.ma).

The survey consists of two parts, the first contains information on the socio-demographic parameters of the 
students, and the second concerns questions related to internet access and coverage tools, to the use of social networks, the quality of the courses given online and the difficulties encountered during the lockdown which took place from March 20 to May 20, 2020.

In order to ensure better reliability of the items of the questions asked, we calculated the Cronbach index, a value between 0.7 and 0.9 is acceptable for carrying out an exploratory study [5] [6].

Regarding the statistical methodology, it is based on two components:

1. The descriptive section: the objective of this first section is to draw the socio-demographic profile of the respondents. The data are presented in the form of tables, figures and means \pm standard deviation.

2. The analytical section: the objective of this section is to determine the link between the dependent variable and the other variables studied. In order to verify this link, we used the odds ratio calculation and the Chi2 test.

In this article, we have set the significance level at 0.05 .

\section{Results}

Our survey consists of 145 students with an average age of 22 , with $87 \%$ being between 21 and 23 years old. The sex ratio is 1.5 , it is in favor of the male sex ( $p$ value $<0.05$ ).

Regarding the discipline, we found that students from higher schools are those who cooperated the most with $70 \%$ of responses.

Psychometrically, we found a satisfactory value for the Cronbach index (0.8) which, based on the scores recorded on each item, explains the homogeneity of the items in the questionnaire studied. This value shows that the questionnaire is reliable in the Moroccan context.

Regarding internet access, we found that $84 \%$ of respondents have internet access compared to $16 \%$ of those who do not. With a highly significant differentiation between the two responses $(\mathrm{Pv}<0.001)$.

Ibn Tofail University has made GOOGLE MEET and GOOGLE CLASSROOM platforms available to teachers and students to provide distance education. $38 \%$ of students responding to the survey used social media for online learning, and $62 \%$ of students used dedicated distance learning platforms like ZOOM, GOOGLE MEET and GOOGLE CLASSROOM - with a significant differentiation between the two values $(\mathrm{p}<0.05)$.

We found that $61 \%$ of students said they mastered the platforms made available by Ibn Tofail University to provide distance education, compared to $39 \%$ who did not master these platforms.

We also found that $40 \%$ of the students who answered this questionnaire said that their main concern during lockdown was the use of social networks such as Facebook, Instagram, Snapchat, Tic-toc, etc. In addition, we noted that the students also spent their time studying (29\%), cooking (11\%) and reading $(6 \%)$ with a significant differentiation between the modalities.

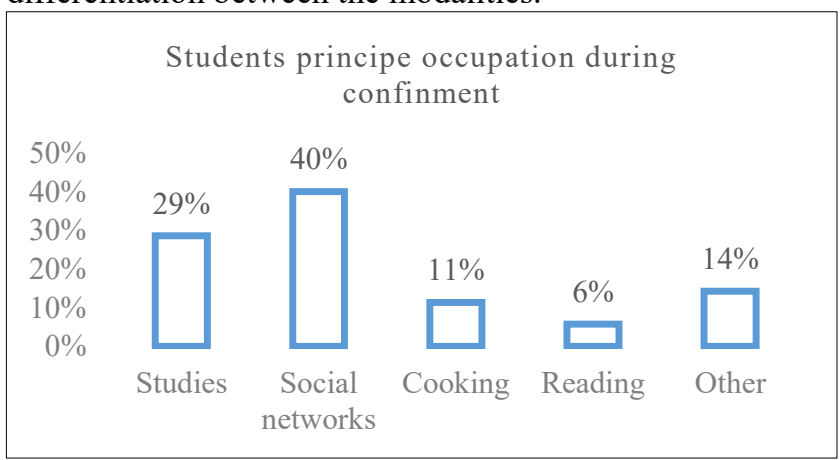

Fig. 1. The main concern of students during confinement

Regarding the importance of the professor's presence in university education, $49 \%$ of students said they were not in contact with their professors, against $51 \%$ declared that they had been in contact with their professors during the period of distance learning following the confinement of the Moroccan population.

$41 \%$ of students found it difficult to learn online, compared to $59 \%$ of students who did not have a problem with distance learning.

It remains to be clarified that $78 \%$ of students are not satisfied with the pedagogical follow-up of teachers during distance education.

During the confinement period, almost all of the students interviewed had a poor experience of confinement with a percentage of $73 \%$ with a highly significant differentiation between the two modalities $(\mathrm{Pv}<0.001)$.

Also, $91 \%$ of the students interviewed stated not being ready to take their end-of-year exams after confinement, without having face-to-face contact with their professors and classmates, and only $23 \%$ of students felt they had the ability to take exams remotely through the platforms made available by Ibn Tofail University.

In order to determine the factors that influence distance learning, we carried out a chi2 test by setting the assimilation of the course given online as the dependent variable.

Table 1 - The link between the dependant variable (online class assimilation) and the independant variables

\begin{tabular}{|c|c|c|c|c|c|c|}
\hline \multirow[t]{2}{*}{$\begin{array}{l}\text { Independe } \\
\text { nt } \\
\text { variable }\end{array}$} & \multicolumn{2}{|c|}{$\begin{array}{l}\text { Dependan } \\
\text { t variable: } \\
\text { online } \\
\text { class } \\
\text { assimilati } \\
\text { on }\end{array}$} & \multirow[t]{2}{*}{$\begin{array}{l}\text { Chi } \\
2 \\
\text { valu } \\
\text { e }\end{array}$} & \multirow[t]{2}{*}{$\begin{array}{l}\text { Odd } \\
\mathrm{s} \\
\text { rati } \\
\text { o }\end{array}$} & \multirow[t]{2}{*}{$\begin{array}{l}\text { Confiden } \\
\text { ce } \\
\text { interval } \\
\text { at } 95 \%\end{array}$} & \multirow[t]{2}{*}{ Pvalue } \\
\hline & No & Yes & & & & \\
\hline \multicolumn{7}{|l|}{ Sex } \\
\hline Male & 58 & 29 & $\begin{array}{l}19,4 \\
5\end{array}$ & 4,8 & $\begin{array}{l}{[2,35-} \\
9,9]\end{array}$ & $\begin{array}{l}0,001 * \\
* *\end{array}$ \\
\hline Female & 17 & 41 & & & & \\
\hline
\end{tabular}




\begin{tabular}{|l|l|l|l|l|l|l|}
\hline Faculties & 43 & 15 & $\begin{array}{l}30,3 \\
4\end{array}$ & 7,5 & $\begin{array}{l}{[3,55-} \\
15,98]\end{array}$ & $\begin{array}{l}0,001^{*} \\
* *\end{array}$ \\
\hline Schools & 24 & 63 & & & & \\
\hline The student's residence zone \\
\hline Rural & 25 & 13 & $\begin{array}{l}11,8 \\
9\end{array}$ & 3,7 & $\begin{array}{l}{[1,74-} \\
8,28]\end{array}$ & $\begin{array}{l}0,001^{*} \\
* *\end{array}$ \\
\hline Urban & 36 & 71 & & & & \\
\hline The student's psychological condition during confinement \\
\hline Bad & 85 & 21 & 31 & 9,11 & $\begin{array}{l}{[3,97-} \\
20,91]\end{array}$ & $\begin{array}{l}0,001^{*} \\
* *\end{array}$ \\
\hline Good & 12 & 27 & & & & \\
\hline
\end{tabular}

We noted a high significance between the different factors cited and the dependent variable which is the assimilation of the distance course with a Pvalue of 0.001, with:

According to the calculation of the odds ratio, the factors that influence the assimilation of the distance course during the period of confinement are:

- The sex of the respondents: odds ratio $=4.8 ; \mathrm{CI}=$ [2.35-9.9]; P-value $=0.001$

- The type of institution to which the students belong: odds ratio $=7.5 ; \mathrm{CI}=[3.55-15.98] ; \mathrm{P}$-value $=0.001$

- The geographic category of the place of residence: odds ratio $=3.7 ; \mathrm{CI}=[1.74-8.28] ; \mathrm{P}$-value $=0.001$

- The psychological state of the students during the administration of the questionnaire (the second and third months of confinement): odds ratio $=3.97$; CI $=[3.97-20.91] ;$ P-value $=0.001$.

On the psychological level, loss of motivation is the most important constraint in maintaining distance learning: 55\% of students said they had loss of motivation as a major constraint, against $28 \%$ of students who do not have the necessary material or electronic equipment, while $17 \%$ of the respondents said being around family and friends during the day made studying difficult.

\section{Discussion}

The transfer and sharing of information as well as the interactions between individuals have become easy and instantly accessible, regardless of a person's geographic location. Therefore, today, it is becoming obvious and commonplace to communicate in a virtual environment similar to the "real" environment in which we live.

For several years now, platforms dedicated primarily to online learning (e-learning) such us Udemy, Coursera, EdX have multiplied and developed to meet the growing need of e-learning among learners and students. Some universities have also developed their own platforms in order to provide more flexible and accessible content to their students. Elearning was the only solution that enabled students around the world to continue learning in times of crisis.

Today, the coronavirus pandemic has affected educational systems worldwide, leading to the widespread closure of schools in the affected countries. As of 28th March, 2020, over 1.7 billion learners were out of school because of the pandemic [7]. This has reminded us of the importance of the internet and technology, thanks to which Morocco, and many other countries, have been able to ensure the continuity of online courses despite the cessation of all activity during the lockdown.

The new mode of learning was introduced in Moroccan universities with many challenges and obstacles related to the lack of preparation to the educational use of the internet, the lack of means and methods needed to ensure the most productive and engaging learning environment. It is in this context that we conducted our survey of students at Ibn Tofail University to ascertain the factors that had an impact on this process of online learning.

Moroccan higher education system includes universities, schools and technological institutes. The studies are organized on the same European LDM model : License in 3 years, Masters in additional 2 years and doctorate in additional 3 years; an academic year is composed of 2 semesters. Students from higher schools are often less numerous than students enrolled in faculties. Higher schools in Morocco set high thresholds for students who want to access them, the thresholds vary between 14 and 18 of average at the baccalaureate depending on the discipline. There are no thresholds for entering college, and many students enroll in college pending admission to school or abroad.

Access to the internet is one of the challenges encountered during the lockdown period. Whether because of the lack of financial means, or the quality of the Internet coverage which has often been disrupted, some students have not been able to follow their studies online continuously without technical problems.

In fact, in the absence of prior training to the use of Google services launched by the University, several professors have created groups on mobile applications such as WhatsApp (which replace Google CLASSROOM) dedicated to sharing information, explanations, courses and exercises in the goal of benefiting the greatest number of students who do not have computers or adequate equipment needed to use the platform deployed by the university, given that the majority of students have smartphones. "Lives" (live online video recordings) on social networks like Facebook have also been organized for the same reasons (which replace Google MEET) and to keep a solid link between the professors and their students. The use of social networks for the purpose of learning has given rise to networks of educational exchanges between professors and students, and also between students. A platform dedicated to distance learning can be effective when it is easy to use, reliable, and popular within the users [8]. The use of social networks for the purpose of learning succeeds thanks to the links that are created through sharing and communication via tools that are used in everyday life because of their accessibility and their free availability, especially in developing countries [9] where it is difficult to implement specific tools for distance education compatible with the education system. The creation of WhatsApp groups allows exchange of information and ideas in safe 
environments, where academic discussions can take place with the professors as a participant and security facilitator / moderator. The opportunity of sharing, reading, viewing, listening, writing, and monitoring ability [10] that WhatsApp offers allows teacher and students to share information and feedback in class, but also to communicate with peers on the fears and achievements of each quickly and easily. A direct correlation has been found between rapid teacher response and cognitive learning / emotional learning and student motivation [11].

Not finding the time to learn online is a problem that often comes up with students who do not find the balance between online learning, family life, social life which, during confinement, was mostly virtual, and activities developed in parallel. This difficulty may be due to the non-preparation for using the means and tools made available to students to take their courses online.

On the psychological level, the loss of motivation (55\%) is the most important constraint in maintaining distance studies. Motivation is an important factor that affects people's lives, their success and their careers. This is the factor that influences not only learning, but also work and resilience during difficult times [12] like the health crisis and the state of alert we are experiencing today.

E-learning is a new form of learning that requires new solutions. The work of Deci and Ryan emphasizes the dynamic relationship between the learner and his environment, they highlight the importance of determinism and student competence, but also the need for affiliation (feeling of belonging) [13].

The school, like the university, allows students to acuire and develop professional and interpersonal skills, it also allows the creation of students' networks that enhances their ability to work together (team work), and benefit from social and group dynamics; it also strengthens the feeling of belonging. This feeling of belonging, as well as the feeling of understanding and learning influences the student's motivation.

In 2007, Tom Franklin and Mark Van Harmelen have already conducted a study on the Information Communication Technology for learning and teaching in higher education. They found that ICT represents a great opportunity to create an environment of exchange between the web users, benefiting sharing and collaboration through webblogs, wikis (a website that authors use to publish content/ articles), social networking systems, etc. [14]. "Web 2.0 for Content for Learning and Teaching in Higher Education", Bristol, R.-U. : Joint Information Systems Committee. Today, the key to online education is to create a solid network that attract and motivate students to keep learning online, using digital platforms that match the needs of Moroccan students.

Contact with the teacher is important in the learning process, students who could not keep a continuous contact with their professors also reported not having assimilated the course or having had difficulty understanding the classes they took online during lockdown. Contact with the teacher can be a source of motivation for some students who need to be encouraged, to participate in group class projects, and to engage face to face conversations with their professors or fellow students. According to Najmul and Yukun, when the student has high expectations, it is rare that he expresses high satisfaction with the course, this finding is all the more noted when the professor does not succeed in motivating his students during the classes assigned on line [15] (Najmul \& Yukun, 2020). The factor "motivation" is a factor that is mentioned several times by the students.

Some of the direct consequences of confinement include boredom, social isolation, stress, lack of sleep, depression and suicidal behavior, addictive behavior, domestic violence [16]. Moreover, in distance training even under "normal" circumstances, isolation is the cause of many dropouts [17]. The degree to which a students that is enrolled in an online class perceives himself in relation to his teachers, peers and institution [18] remains important for the assimilation of the course.

The majority of students do not consider themselves capable of answering exams based solely on resources / information / courses given online only. The difficulty or impossibility of accessing to a fast and reliable coverage to the internet for many students, especially those who live in rural areas, or those who do not have the means to acquire the necessary material which allows them to follow online courses, has influenced the quality of online teaching / learning.

Indeed, we previously quoted in this article that only $23 \%$ of students felt they had the ability to take the exams online through the platforms made available by Ibn Tofail University. This result can be justified, as discussed in this article, by the lack of means, access to the internet, its speed or its absence, the psychological state of the students, the lack of communication, the lack of training on the use of these platforms, etc.. Students do not feel ready to take the exams right after the confinement ends, let alone take the exams via the Google MEET and CLASSROOM platforms.

\section{Conclusion}

In this article, we focused on distance education in a fairly difficult, new and above all unexpected conditions caused by the Covid-19 pandemic, which challenged the educational institution in Morocco to achieve quality education during this time of crisis.

It is in this sense that we have tried to highlight the factors that influence the understanding and assimilation of courses followed online by Ibn Tofail University students, and the way in which students and teachers of the same University have, despite the difficulties encountered, been able to handle this situation.

Following our empirical analysis, internet access, platforms and IT tools are the elements on which we have based ourselves. Out of a convenience sample of 145 students, $84 \%$ had internet access, a fairly large percentage. That said and despite the availability of this resource, $78 \%$ of them 
were dissatisfied with the pedagogical follow-up of their teachers, claiming $(73 \%)$ to have badly internalized this period of sedentary lifestyle that had befallen them. This surprise effect, which prompted these students to change their habits, had a negative and significant impact on their motivation, their involvement and their interaction.

Morocco today has learned important lessons from this unexpected distance learning experience, and several universities including Ibn Tofail's, have started integrating online programs to reach all categories of students. 


\section{Bibliography}

[1] Ministère de la santé. Le Maroc annonce l'enregistrement du premier cas du nouveau Coronavirus. 25 mai 2020. Available on : https://www.sante.gov.ma/Pages/communiqu $\% \mathrm{C} 3 \% \mathrm{~A}$ 9s.aspx? communiqueID $=355$

[2] K. Rahali, Z. Abdili, A. Khohmimidi, M. Elhamzaoui, R. Serghini, K. Jabari, ... A. Chaouch (2020). Ibn Tofail's University students' satisfaction evaluation towards distance learning and its impacts on the students' mental health during the Covid 19 Confinement. Bangladesh Journal of Medical Science, 51-57.

[3] C. Chou, H Peng, C.-Y. Chang (2010). The technical framework of interactive functions for coursemanagement systems: Students' perceptions, uses, and evaluations. ScienceDirect, 1004-1017.

[4] E. Erichsen, D. Bolliger (2010). Towards understanding international graduate student isolation in traditional and online environments. Education Tech Research Dev., 309-326.

[5] R. A. Johnson, D.W. Wichern (2008). Applied Multivariate Statistical Analysis. New Jersey: Pearson Prentice Hall.

[6] L.J. Cronbach (1951). Coefficient alpha and the internal structure of tests. Psychometrika, 279-334.

[7] C. Owusu-Fordjour, C. Koomsom, D. Hanson (2020). The impact of Covid-19 on learning - the perspective of the Ghanaian student. European Journal of Education Studies, 12.

[8] J. Attewell (2005). From research and development to mobile learning: Tools for Education and training providers and their learners. 4th World Conference on mLearning. Cape Town.

[9] A. Bere (2012). A comparative study of student experiences of ubiquitous learning via mobile devices and learner management systems at a South African university. 14th Annual conference on world wide web application. Cape Town.
[10] M. Bower (2008). Affordance analysis - Matching learning tasks with learning technologies. Educational Media International, 3-15.

[11] K. Church, R. Oliveira (2013). What's up with Whatsapp? Comparing Mobile Instant Messaging Behaviors with Traditional SMS. 15th International Conference on Human-Computer Interaction with Mobile Devices and Services, (pp. 352-361). Munich.

[12] S. Hubackova (2014). Motivation in eLearning in University study. International Conference on Education \& Educational Psychology 2013 (ICEEPSY 2013) (pp. 309-313). Elsevier Ltd.

[13] E. L. Deci, R. Ryan (1991). A Motivational Approach to Self: Integration in Personality. Current theory and research in motivation, 237-288.

[14] T. Franklin, M. Van Harmelen (2007). Web 2.0 for Content for Learning and Teaching in Higher Education. Bristol, R.-U. : Joint Information Systems Committee

[15] H. Najmul, B. Yukun (2020). Impact of "e-Learning crack-up" perception on psychological distress among college students during COVID-19 pandemic: A mediating role of "fear of academic year loss". Children and Youth Services Review.

[16] A. Mengin, Alle, M., Rolling, J., Ligier, F., Schroder, C., Lalanne, L., . . G Giersch, A. (2020). Conséquences psychopathologiques du confinementPsychopathological consequences of confinement. L'ancéphale, 43-52.

[17] C. Dussarps, D. Paquelin (2014). Pratiques sociales en formation à distance. Netcom, 257-268.

[18] Karen Ragoonaden, Les interactions collaboratives dans des cours à distance sur Internet, Université de Montréal, 2001, 20 juin 2020 available on : https://papyrus.bib.umontreal.ca/xmlui/bitstream/hand le/1866/6795/these.pdf 